\title{
O PROCESSO DE FUNDIÇÃO PARA FABRICAÇÃO DE TRÊS TIPOS DE FERRO FUNDIDOS
}

\section{THE CASTING PROCESS FOR THE MANUFACTURE OF THREE TYPES OF CAST IRON}

\author{
Alexandre Tiago Guidugli ${ }^{\mathrm{I}}$ \\ Rafael dos Santos ${ }^{\text {II }}$ \\ Omar Maluf ${ }^{\text {III }}$ \\ Alessandro Fraga Farah ${ }^{\text {IV }}$ \\ Maria Aparecida Bovério $\mathrm{V}$
}

RESUMO

O presente trabalho teve como objetivo geral obter três diferentes tipos de ferro fundido com os mesmos elementos químicos finais, diferentes métodos e taxas de resfriamento, obtendo-se o ferro fundido nodular, o ferro fundido branco e o ferro fundido cinzento. Para isso, foi realizada uma pesquisa bibliográfica e uma pesquisa laboratorial, no laboratório de fundição, da Faculdade de Tecnologia (FATEC) de Sertãozinho/SP. Através de análise química com a espectrometria e a metalografia concluiu-se que com os mesmos elementos químicos e uma alteração na taxa de resfriamento obtido em diferentes moldes é possível obter os materiais ferro fundido nodular, ferro fundido branco e ferro fundido cinzento, com suas constituições e durezas específicas e esperadas.

Palavras-chave: Fundição. Tipos de Ferro Fundido. Resfriamento. Composição Química.

\begin{abstract}
The present work had as general objective to obtain three different types of cast iron with the same final chemical elements, different methods and cooling rates, obtaining nodular cast iron, white cast iron and grey cast iron. For this, we conducted a bibliographic research and laboratory research, in the Foundry Laboratory, of the Faculty of Technology (FATEC) of Sertãozinho/SP. Through chemical analysis with spectrometry and metallography it was concluded that with the same Chemical elements and a change in the cooling rate obtained in different molds is possible to obtain the materials nodular cast iron, white cast iron and grey cast iron, with their constitutions and dures specific and expected.
\end{abstract}

Keywords: Casting. Types of cast iron. Cooling. Chemical composition.

I Estudante do Curso Superior de Tecnologia em Mecânica: processos de soldagem da Faculdade de Tecnologia (FATEC) de Sertãozinho - São Paulo - Brasil. E-mail: alexandretiagoguidugli@gmail.com

II Estudante do Curso Superior de Tecnologia em Mecânica: processos de soldagem da Faculdade de Tecnologia (FATEC) de Sertãozinho - São Paulo - Brasil. E-mail: ra.santosstz42@gmail.com

III Prof. Pós-Dr. da Faculdade de Tecnologia (FATEC) de Sertãozinho - São Paulo - Brasil. E-mail: omar.maluf@fatec.sp.gov.br

IV Prof. Dr. da Faculdade de Tecnologia (FATEC) de Sertãozinho - São Paulo - Brasil. E-mail: alfatec2011@bol.com.br

V Profa. Pós-Dra. da Faculdade de Tecnologia (FATEC) de Sertãozinho - São Paulo - Brasil. E-mail: mariaboverio@hotmail.com 


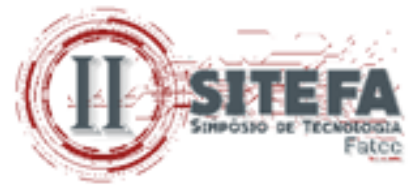

Data de submissão do artigo: 15/07/2019.

Data de aprovação do artigo: 22/08//2019.

DOI:

\section{INTRODUÇÃO}

Este artigo apresenta os resultados da pesquisa que investigou o processo de fundição para fabricação de três tipos de ferro fundidos, através do controle de resfriamento no processo de fundição, contendo a mesma carga final de elementos químicos.

O objetivo geral desta pesquisa é obter três diferentes tipos de ferro fundido com os mesmos elementos químicos finais e diferentes métodos de resfriamentos, obtendo-se o ferro fundido nodular, o ferro fundido branco e o ferro fundido cinzento. Os objetivos específicos desta pesquisa são fundir os elementos da carga calculada e controlar os resfriamentos.

Ferro fundido nodular é excelente na usinabilidade, com possibilidade de deformação a quente, grande resistência a desgaste e boa fluidez. O ferro fundido branco contém elevada resistência a compressão a brasagem, é muito duro e frágil, não pode ser maquinado, a soldadura é impossível de ser realizada e possui baixo custo. O ferro fundido cinzento contém elevada fluidez, boa usinabilidade, grande resistência a desgaste, contém concentrações de tenções e soldadura difícil (BOSE FILHO, 2018).

A finalidade foi a de verificar se através da mesma carga de fundição com os mesmos elementos químicos, mais a adição da liga de magnésio (que facilitará a formação dos nódulos) é possível obter mais de um tipo de ferro fundido. O problema é investigar se "é possível obter mais de um tipo de ferro fundido com os mesmos elementos químicos finais controlando-se a taxa de resfriamento?"

A hipótese desta pesquisa é a de que é possível obter mais de um tipo de ferro fundido com os mesmos elementos químicos finais, controlando-se apenas o resfriamento, uma vez que foram usados diferentes meios de resfriamento (coquilha) para se chegar no objetivo da pesquisa.

Como procedimentos metodológicos foram realizados experimentos através de ensaios de metalografia, ensaio de dureza e ensaio de espectrometria nos laboratórios da FATEC de Sertãozinho/SP, com resultados fotográficos e tabelados.

\section{FERRO FUNDIDO}

O ferro fundido é considerado uma liga de Fe, C, e Si composto ainda por $\mathrm{Mn}, \mathrm{S}$ e P; devendo, se necessário, ainda, adicionar outros tipos de ligas. A finalidade do ferro fundido é a formação de grafita. Para a formação de grafita o carbono geralmente se apresenta parcialmente livre em forma de veios, lamelas e nódulos, devido a quantidade de carbono acima de $2 \%$, é o teor acima do que pode ser retido na solução sólida da austenita (VIDAL, 2013).

O processo de fusão consiste em uma alteração física do estado sólido para o líquido, seguido de uma série de reações de oxidação-redução. Os materiais que formam a carga definirão a composição química da liga de ferro e da escória formada. Uma vez que a composição interfere na microestrutura e nas propriedades mecânicas do ferro fundido, deve ser controlado o teor de elementos de liga e impurezas na composição inicial da carga (SCHEID, 2016).

A velocidade de resfriamento durante a solidificação varia com a espessura das peças moldadas, em elevadas velocidades de resfriamento (que ocorrem normalmente em seções finas 


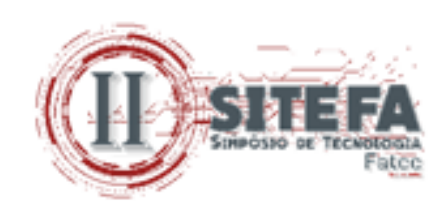

ou nas áreas junto às paredes do molde) não há tempo para decompor a cementita, de modo que, dependendo dos teores de carbono e de silício, ocorre pouca ou nenhuma grafitização, e há tendência para formar-se ferro fundido branco. Com as velocidades de resfriamento lentas das seções mais espessas, ocorre uma grafitização (dependente sempre do teor de silício) e a estrutura será constituída essencialmente de perlita e grafita. A velocidade de resfriamento influi também na forma, distribuição e tamanho dos veios de grafita. Quanto maior for essa velocidade, mais refinada será essa microestrutura (SILVA, 2007).

Os principais tipos de ferro fundido são: cinzento, branco e nodular. O ferro fundido cinzento apresenta-se micro estruturalmente com carbono na forma livre, a grafita, e em morfologia de lamelas, dispersos numa matriz ferrítica, ferrítica-perlítica ou perlítica. Nesse caso, os principais elementos de liga são o carbono e o silício, podendo haver outros, como o manganês, cromo e cobre que irão conferir aos fundidos outras características exigidas. Sua superfície de fratura exibe uma cor cinza escuro (MELLO, 2003).

$\mathrm{O}$ ferro fundido branco apresenta-se micro estruturalmente com a maioria do carbono na forma combinada, resultante da baixa porcentagem de silício e carbono. Sua matriz normalmente é perlítica e ledeburítica. A sua maior particularidade é a resistência ao desgaste. Sua superfície de fratura exibe uma cor clara e brilhante (MELLO, 2003).

$\mathrm{O}$ ferro fundido nodular apresenta-se na forma microestrutural como carbono livre na forma de nódulos, numa matriz ferrítica, ferrítica-perlítica ou perlítica, o que comina a esse tipo de ferro fundido, características mecânicas superiores àquelas do ferro fundido cinzento. É obtido por alterações químicas na composição do material no estado líquido. Sua superfície de fratura exibe uma cor prateada (MELLO, 2003).

Dos constituintes citados, a ferrita é a solução sólida do carbono em ferro alfa, de estrutura CCC. A cementita, é o carboneto de ferro (Fe3C), de estrutura ortorrômbica e alta dureza. A perlita é composta de ferrita e lamelas de cementita. A ledeburita, ocorre nos ferros fundidos brancos e é um constituinte formado de pequenos glóbulos de perlita, sobre um fundo de cementita; por isso, apresenta elevada dureza (SILVA, 2007).

A Tabela 1 mostra a composição química nominal de alguns ferros fundidos e a tabela 2 apresenta a dureza dos ferros utilizados.

Tabela 1 - Composição química dos ferros fundidos cinzento, branco e nodular

\begin{tabular}{lccccc}
\hline Ferros & C \% & Si \% & Mn \% & S \% & P \% \\
\hline Bundidos & $1,8-3,6$ & $0,5-1,9$ & $0,25-0,80$ & $0,06-0,20$ & $0,06-0,18$ \\
Cinzento & $2,5-4,0$ & $1,0-3,0$ & $0,25-1,0$ & $0,02-0,25$ & $0,05-1,0$ \\
Nodular & $3,0-4,0$ & $1,8-2,8$ & $0,10-1,0$ & 0,03 máx. & 0,10 máx. \\
\hline
\end{tabular}

Fonte: Chiaverini (2008)

Tabela 2 - Tabela de Dureza

\begin{tabular}{l|c}
\hline Material & Dureza Média (HB) \\
\hline Ferro Fundido Cinzento & $170-200$ \\
\hline Ferro Fundido Branco & $450-600$ \\
\hline Ferro Fundido Nodular & $150-180$ \\
\hline
\end{tabular}

Fonte: elaborada pelos autores (2019) 


\section{(iii) $\sin$}

\subsection{Diagrama Ferro Carbono}

A Figura 1 apresenta o diagrama binário da liga $\mathrm{Fe}-\mathrm{C}$, para teores de carbono de até $6,7 \%$, pois o carbono forma com o Ferro o composto $\mathrm{Fe}_{3} \mathrm{C}$, a cementita, que contém aproximadamente $6,67 \%$ de C. (POLI USP, 2011).

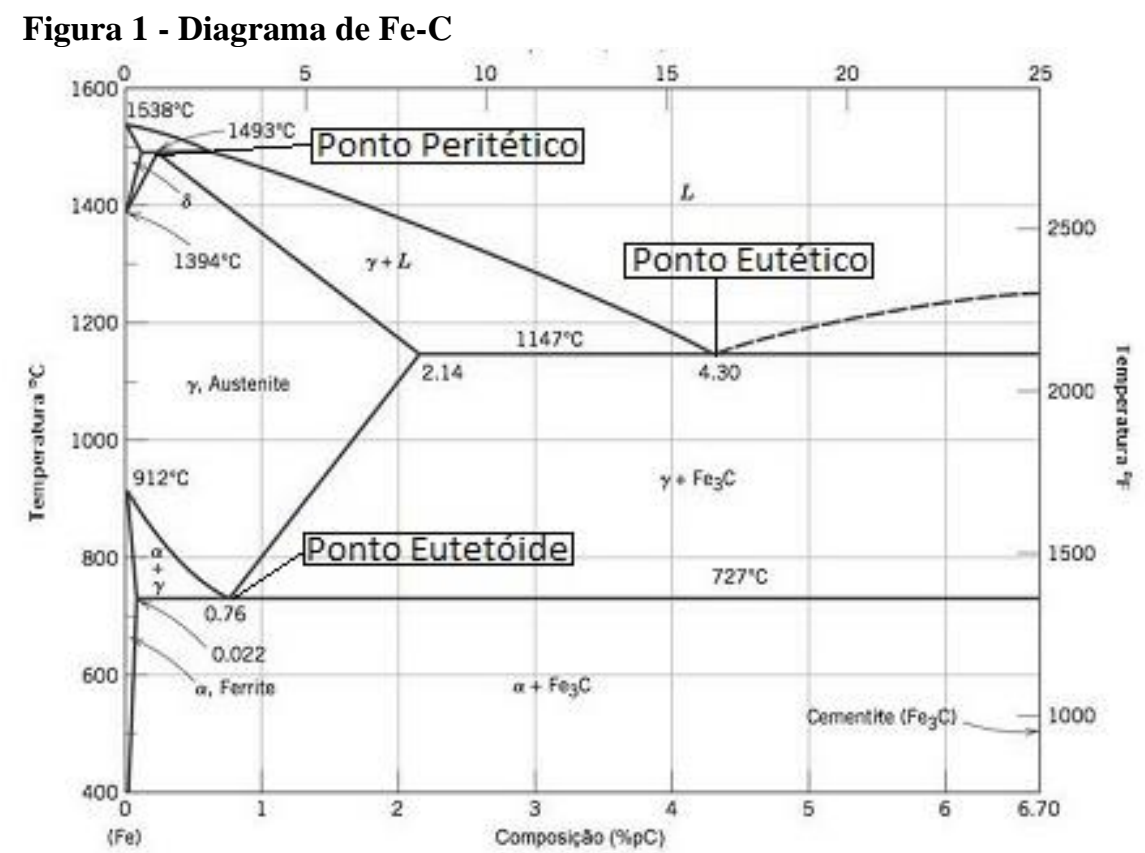

Fonte: Callister Júnior (2002)

O conjunto de pontos, temperatura/composição que representa o máximo de solubilidade (saturação) de uma fase sólida numa fase líquida é situada acima na faixa de líquidos. O ponto invariante peritético, no qual a composição da fase líquida em equilíbrio termodinâmico com as fases sólidas, não pode ser definido em termos de quantidades positivas das fases sólidas. A solução sólida ou composição pode variar dentro de certos limites finitos, sem que se forme uma nova fase adicional, a não ser a fase que a constitui (MALUF et al., 2014).

O ponto invariante eutético representa um ponto de um sistema, para o qual há acréscimo ou retirada de energia ao sistema, resultando num aumento ou diminuição, simultânea, da fase líquida à custa das fases sólidas. O ponto invariante eutetoide é composto exclusivamente por fases cristalinas, no qual o grau de avanço da reação, por alteração da energia do sistema, resulta na alteração das proporções entre as fases sólidas (MALUF et al., 2014)

O diagrama Fe-C, exibe dois eutéticos naturais de dois equilíbrios: estável e metaestável. O eutético estável é constituído pela austenita e grafita, e o eutético metaestável por austenita e cementita (MALUF et al., 2014)

\subsection{Efeitos da composição química}

Os efeitos da composição química são: adição do fósforo, do silício, do manganês, enxofre e carbono, apresentados nas subseções a seguir. 


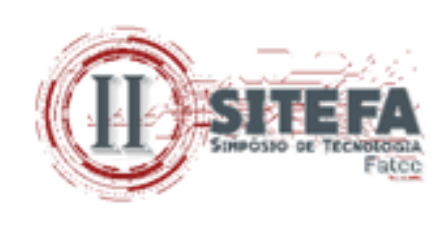

\subsubsection{Efeito da adição do Fósforo}

O fósforo tem o efeito de diminuir as temperaturas do eutético estável e do eutético metaestável. A diminuição dos dois eutéticos causa o aumento da fluidez e o preenchimento de paredes finas. $\mathrm{O}$ fósforo em ferro fundido é um elemento grafitizante, em teores de até $0,06 \%$ é solúvel em ferro, e em teores crescentes diminui o teor de carbono eutético, sendo sua relação, igual à do silício, correspondendo a $1 / 3$ do carbono (ROSARIO, 2012).

O fósforo contém em teores acima de $0,06 \%$, é fortemente segregado para o líquido durante a solidificação, aumentando o risco da formação de eutéticos ricos em fósforo, que no caso particular dos ferro-carbono ganha o nome de esteadita. A esteadita é um eutético fosforoso que tem um ponto de fusão perto de $930^{\circ} \mathrm{C}$, e em torno de $200^{\circ} \mathrm{C}$ inferior à temperatura de solidificação eutética dos ferros fundidos. Como é o último componente a solidificar ocorre em limites ou em contornos das células eutéticas (ROSARIO, 2012).

\subsubsection{Efeito da adição do Silício}

Segundo Rosário (2012), o silício tem a finalidade de aumentar a temperatura do eutético estável e de diminuir a temperatura do eutético metaestável. O silício é o componente mais importante na liga ferro-carbono, sendo o fator principal no controle da estrutura e das propriedades mecânicas.

Uma liga de alto carbono com elevado teor de silício promove uma rápida decomposição da cementita, promovendo a formação da grafita e impedindo a formação da cementita durante a solidificação e transformação pró-eutetóide (ROSARIO, 2012).

\subsubsection{Efeito da adição do Manganês}

O manganês tem como alvo principal neutralizar o enxofre, mas quando em excesso tende a atuar como perlitizante. O enxofre é considerado, em princípio uma impureza que se não compensada pelo manganês forma sulfetos de ferro que tendem a segregar para o contorno das células eutéticas, atuando como grafitizantes. O enxofre deve ser neutralizado como sulfeto de manganês e, portanto, é indicado que o nível de manganês seja na proporção de cinco vezes o teor de enxofre (ROSARIO, 2012).

\subsubsection{Efeito da adição do Enxofre}

A quantidade de enxofre elevado é danosa pela formação de escória e borra, devendo ser dessulfurado com carbeto de cálcio até alcançar o valor máximo indicado ou menor indicado (ROSARIO, 2012).

\subsubsection{Efeito da adição de Carbono}

O carbono é o elemento de liga básico que determina, obviamente, a quantidade de grafita e/ou cementita que pode se formar nos ferros fundidos (ROSARIO, 2012). 


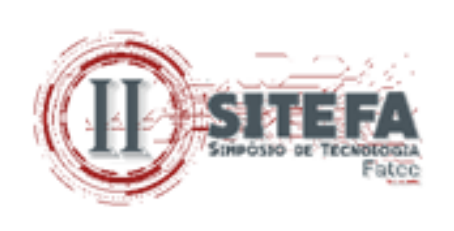

\section{PROCEDIMENTOS METODOLÓGICOS}

Os procedimentos metodológicos desta pesquisa fundamentam-se na pesquisa bibliográfica, e tal como definem Barros e Lehfeld (1986) procurou-se encontrar as informações já publicadas na literatura existente.

A partir do conhecimento sobre o assunto realizou-se a pesquisa laboratorial, conforme define Prodanov e Freitas (2013) como aquela que é realizada em situações controladas, em laboratórios, pois precisa de um ambiente de acordo com o estudo a ser desenvolvido, uma vez que o contexto é controlado pelo ambiente de laboratório. A pesquisa laboratorial foi realizada nos laboratórios da FATEC/STZ, laboratório de fundição, laboratório de análise química e no laboratório de microscopia.

\subsection{Materiais e métodos}

Os materiais e métodos utilizados nessa pesquisa, visam obter resultados em consonância com os objetivos dessa pesquisa, dependendo somente dos mesmos materiais usados nos três ferros fundidos, e da velocidade de resfriamento da composição fundida.

Os materiais utilizados foram: 2 tubos 1.1/2" x Schedule 80 x 300mm e 3 moldes de areia. Gusa nodular, Sucata de aço A36, Ferro silício 75 e Ferro silício magnésio.

Os métodos adotados foram:

- Conseguir os materiais que compõem a carga e os tubos que serviram de modelos para o molde e para a coquilha.

- Calcular a carga metálica do forno. moldes.

- Efetuar o carregamento do forno, fundir o metal a $1380^{\circ} \mathrm{C}$, e vazar o metal líquido nos

- Retirar amostras (moedas) para análise química final.

- Deixar as amostras resfriarem em temperatura ambiente a $31 \mathrm{C}^{\circ}$, sendo que as condições de resfriamento para os 3 moldes foram as mesmas em temperatura e condições ambiente do laboratório da FATEC/Stz. A única diferença foi no molde com coquilha que extraiu a temperatura com maior eficiência do que o molde de areia. de dureza.

- Retirar as peças fundidas dos moldes, analisá-las metalograficamente e realizar análise

- Analisar a composição química final das amostras solidificadas.

\section{RESULTADOS E DISCUSSÃO}

Os resultados obtidos neste trabalho são apresentados e discutidos a seguir.

\subsection{Cálculo da carga metálica do forno}

Para o cálculo de carga é necessário saber a composição química que se quer atingir, a das matérias primas, das ferro-ligas e as perdas e ganhos durante a fusão. $\mathrm{O}$ cálculo da carga metálica consiste na mistura e balanceamento dos materiais, uma vez que contêm, em teores variáveis, os elementos químicos necessários à obtenção da liga desejada, conforme anteriormente apresentados na tabela 1.

A Tabela 3 apresenta o cálculo da carga metálica que foi colocada no forno para fundir a liga inicial do ferro fundido base. 


\section{(iii) SIIEFA}

Tabela 3 - Cálculo de Carga Metálica do Forno para fundir a liga inicial do ferro fundido base

\begin{tabular}{|c|c|c|c|c|c|c|c|c|}
\hline \multirow{2}{*}{ Insumo } & \multicolumn{2}{|c|}{ Peso } & \multicolumn{2}{|c|}{ C } & \multicolumn{2}{|c|}{ Si } & \multicolumn{2}{|c|}{ Mn } \\
\hline & $\%$ & kg & $\%$ & kg & $\%$ & $\mathbf{K g}$ & $\%$ & kg \\
\hline Gusa Nodular & 16 & 24 & 4 & 0,96 & 1,5 & 0,36 & 0,1 & 0,024 \\
\hline FeSi75 & 0,27 & 0,4 & & & 75 & 0,31 & & \\
\hline $\begin{array}{l}\text { Total } 1 \\
\text { Cinzento }\end{array}$ & & 30 & 3,23 & 0,97 & 2,3 & 0,69 & 0,14 & 0,41 \\
\hline \multirow[t]{2}{*}{ FeSiMg6 } & \multirow[t]{2}{*}{0,08} & $0,36 / 30 \mathrm{~kg}$ & & & \multirow[t]{2}{*}{50} & 0,18 & & \\
\hline & & $0,12 / 10 \mathrm{~kg}$ & & & & 0,06 & & \\
\hline $\begin{array}{l}\text { Total } 2 \\
\text { Nodular }\end{array}$ & & 30,36 & 3,23 & 0,97 & 2,9 & 0,87 & 0,14 & 0,041 \\
\hline \multirow[t]{2}{*}{ FeSi75 } & \multirow[t]{2}{*}{0,6} & $0,24 / 30 \mathrm{~kg}$ & & & \multirow[t]{2}{*}{75} & 0,18 & & \\
\hline & & $0,16 / 20 \mathrm{~kg}$ & & & & 0,12 & & \\
\hline $\begin{array}{l}\text { Total } 3 \\
\text { Cinzento }\end{array}$ & & & 3,23 & 0,97 & 2,9 & 0,87 & 0,14 & 0,041 \\
\hline
\end{tabular}

Fonte: elaborada pelos autores (2019)

A tabela 3 apresenta a quantidades e os elementos químicos acrescentados em determinadas etapas para a obtenção dos Ferro Fundido nodular e ferro fundido cinzento. A carga Total 3 Cinzento foi utilizada para a obtenção do Ferro Fundido Branco através da alteração da taxa de resfriamento.

\subsection{Análise Química}

As composições químicas foram obtidas por espectrometria ótica, através de um Espectômetro de emissão ótica da marca Spectro, da FATEC de Sertãozinho/SP.

Tabela 4 - Composição química após solidificação das moedas

\begin{tabular}{ccccccccc}
\hline $\begin{array}{c}\text { Composição } \\
\text { química }\end{array}$ & $\begin{array}{c}\mathbf{C} \\
(\boldsymbol{\%})\end{array}$ & $\mathbf{S i}(\boldsymbol{\%})$ & $\begin{array}{c}\text { Mn } \\
(\boldsymbol{\%})\end{array}$ & $\mathbf{P ( \% )}$ & $\mathbf{S ~ ( \% )}$ & $\mathbf{C r}(\boldsymbol{\%})$ & $\mathbf{N i}(\boldsymbol{\%})$ & $\begin{array}{c}\mathbf{F e} \\
(\boldsymbol{\%})\end{array}$ \\
\hline Antes nodular & 3,11 & 2,90 & 0,123 & 0,0964 & 0,0177 & 0,0367 & 0,0192 & 93,6 \\
\hline Depois branco & 3,17 & 2,45 & 0,113 & 0,0872 & 0,0170 & 0,0253 & 0,0089 & 94,1 \\
\hline
\end{tabular}

Fonte: elaborada pelos autores (2019)

As composições analisadas ficaram dentro da faixa esperada (Tabela 1) através dos cálculos da carga metálica (Tabela 3).

\subsection{Ensaio de Dureza}

O ensaio de dureza trata da medida da resistência que um material, quando pressionado por marcadores padronizados em uma deformação plástica permanente localizada com pequena impressão ou risco. (BARBOSA, 2011). O ensaio de dureza foi realizado em durômetro tipo Rockwell, com penetrador esférico de 2,5mm para medição de dureza Brinell (HB), da FATEC DE Sertãozinho/SP.

A Tabela 5 apresenta a média das indentações feitas em cada amostra. 


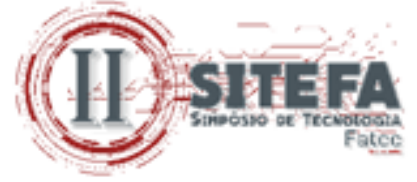

Tabela 5 - Análise da Dureza

\begin{tabular}{l|c}
\hline Material (amostra) & Dureza Média (HB) \\
\hline Ferro Fundido Cinzento & 174 \\
\hline Ferro Fundido Branco & 601 \\
\hline Ferro Fundido Nodular & 187 \\
\hline
\end{tabular}

Fonte: elaborada pelos autores (2019)

As durezas encontradas nas amostras ficaram dentro da faixa de dureza destes tipos de ferros fundidos, conforme anteriormente apresentadas na tabela 2.

\subsection{Ensaio de Metalografia}

O ensaio de metalografia procura relacionar a estrutura íntima do material, com a composição, com as suas propriedades físicas, com o processo de fabricação e com desempenho de suas funções (ROHDE, 2010).

$\mathrm{Na}$ amostra fundida para a obtenção do Ferro Fundido Cinzento, foram encontradas uma matriz $100 \%$ perlítica (1) com carbono na forma livre, grafita, em morfologia de veios (2). Nota-se também a presença de esteadita (3), que é um constituinte de natureza eutética, compreendendo partículas de fosfeto de ferro $\left(\mathrm{Fe}_{3} \mathrm{P}\right)$ e carboneto de ferro $\left(\mathrm{Fe}_{3} \mathrm{C}\right)$. Esse tipo de microestrutura é típico de ferro fundido cinzento (SILVA, 2007). A Figura 2 apresenta a identificação dos constituintes encontrados.

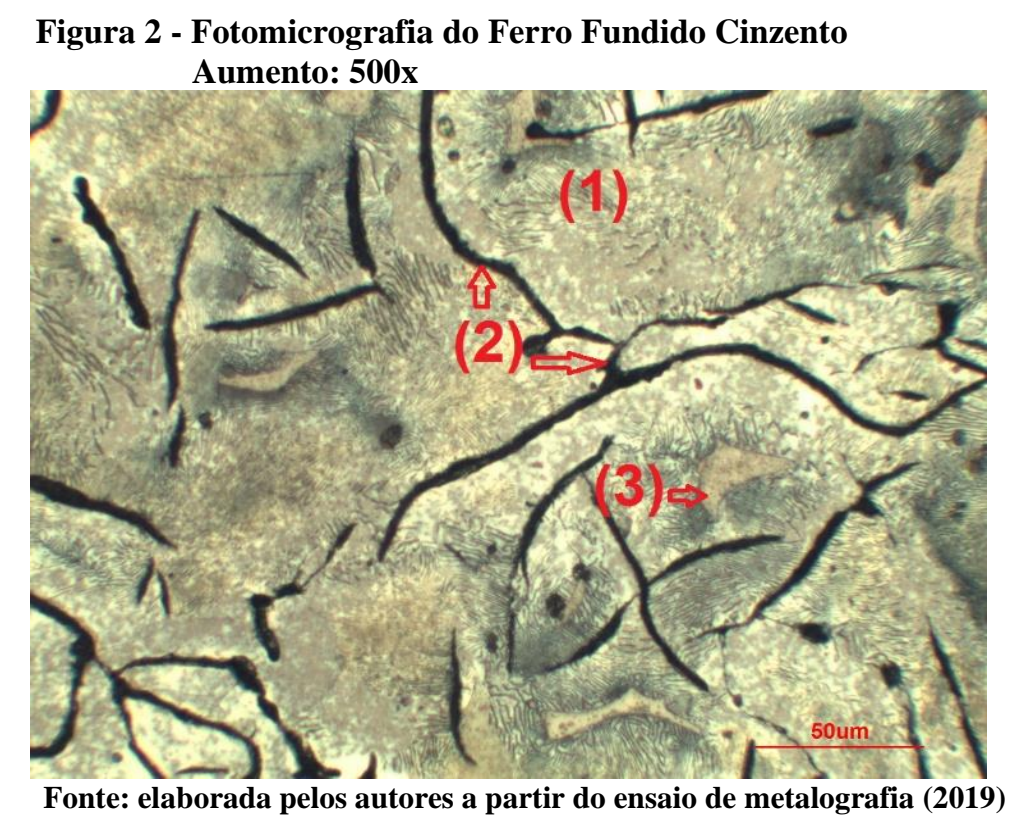

$\mathrm{Na}$ amostra preparada para a obtenção Ferro Fundido Nodular, foram encontradas uma matriz ferrítica (1) com carbono na forma livre, grafita, em morfologia de nódulos (2). Nota-se também a presença de perlita (3) em pequena quantidade. Esse tipo de microestrutura é típico de ferro fundido nodular (VIDAL, 2013). A Figura 3 apresenta os constituintes encontrados. 


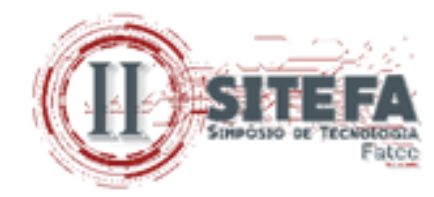

Figura 3 - Fotomicrografia do Ferro Fundido Nodular

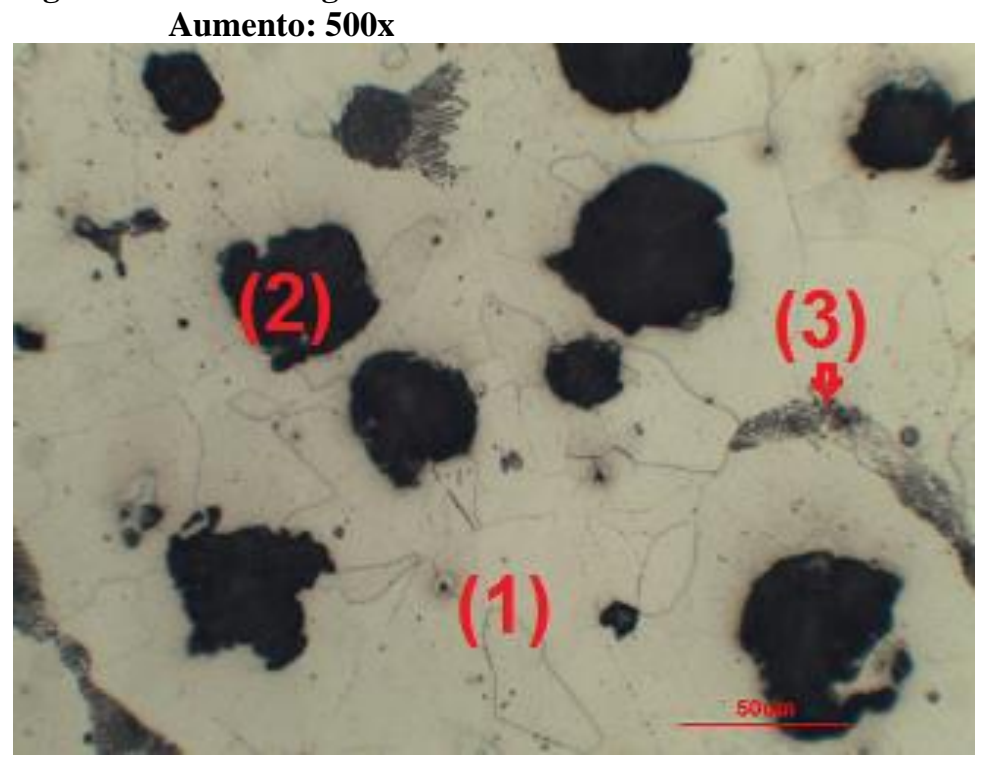

Fonte: elaborada pelos autores a partir do ensaio de metalografia (2019)

Conforme apresentado na figura 4, na amostra que foi resfriada mais rapidamente (coquilhada) para se obter o Ferro Fundido Branco, encontrou-se matriz completamente ledeburítica (glóbulos de perlita (2), sobre um fundo de cementita (1). (SCHEID, 2010).

Figura 4 - Fotomicrografia do Ferro Fundido Branco Aumento: 1000x

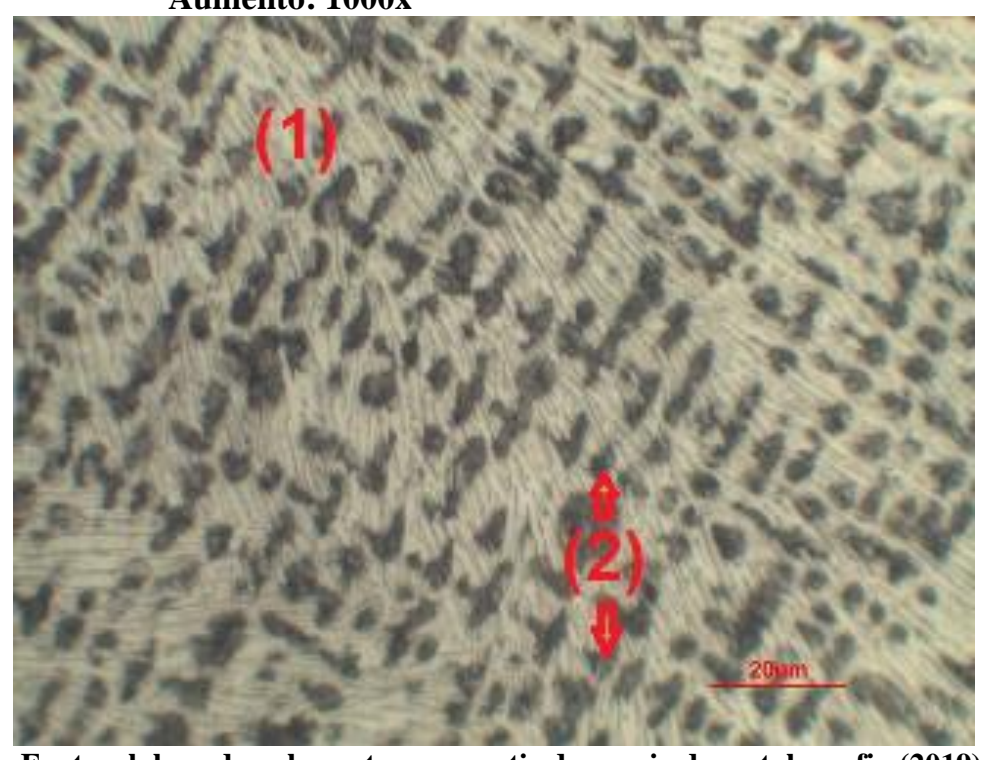

Fonte: elaborada pelos autores a partir do ensaio de metalografia (2019)

\section{CONCLUSÃO}

Com base nos resultados experimentais, realizados nos laboratórios, e que foram apresentados no presente trabalho, as hipóteses de se obter três tipos de Ferros Fundidos com os mesmos elementos químicos e alterando o resfriamento, baseado nos conteúdos bibliográficos, foram confirmadas. Ou seja, com os mesmos elementos químicos e uma 


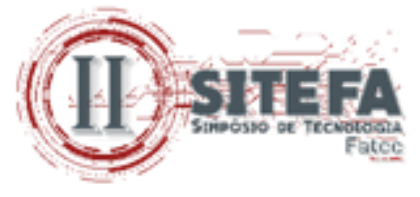

alteração na taxa de resfriamento obtido em diferentes moldes obteve-se os materiais ferro fundido nodular, ferro fundido branco e ferro fundido cinzento.

Os resultados que comprovaram a obtenção destes ferros fundidos foram as devidas características mecânicas, obtidas pelo ensaio de dureza, e características microestruturais, obtidas pelo ensaio metalográfico.

\section{REFERÊNCIAS}

BARBOSA, F. Apostila do Curso de Laboratório de Resistência dos Materiais da Faculdade de Engenharia da UFJF. 2011. Disponível em:

http://www.ufjf.br/lrm/files/2011/05/apostilalrm2011.pdf. Acesso em: 23 nov. 2018

BARROS, A. J. P. de; LEHFELD, N. A. de S. Fundamentos de metodologia: um guia para iniciação cientifica. São Paulo: McGraw-Hill, 1986.

BOSE FILHO, W. W. Ferros Fundidos. Universidade de São Paulo. Escola de Engenharia de São Carlos. Departamento de Engenharia de Materiais. In: disciplina SMM0193-Engenharia e Ciência dos Materiais I. 2018. Disponível em:

https://edisciplinas.usp.br/pluginfile.php/3629494/mod_resource/content/1/Aula\%208-

\%20Ferros\%20Fundidos.pdf. Acesso em: 23 nov. 2018.

CALLISTER JR. W. D. Ciências e engenharia de materiais: Tradução Sérgio Murilo Stamile Soares. 5. Ed. Rio de Janeiro: LTC. 2002. 589p.

CHIAVERINI, Vicente. Aços e Ferros Fundidos. 7. ed. São Paulo: Associação Brasileira de Metalurgia e Materiais, 2008. 599 p. ISBN: 85-86778-48-6

MALUF, O; MILAN, M. T; SPINELLI, D; BOSE FILHO, W. W. Metais uma visão objetiva. 2. ed. São Carlos, 2014.

MELLO, C. A. T. Vida em fadiga de um ferro fundido nodular ferrítico com variações microestruturais. Rio de Janeiro: PUC, Departamento de Ciências dos Materiais e Metalurgia, 2003.

POLI USP. Revista Geologia e Metalurgia. Escola Politécnica da USP. 2011.Disponível em: http://sites.poli.usp.br/geologiaemetalurgia/Revistas/Edi\%C3\%A7\%C3\%A3o\%2011/artigo11. 1.pdf. Acesso em: 16 maio 2019.

PRODANOV, Cleber Cristiano; FREITAS, Ernani Cesar. Metodologia do Trabalho Científico: métodos e técnicas da pesquisa e do trabalho acadêmico. 2. ed. Novo Hamburgo: Feevale, 2013.

ROHDE, R.A. Metalografia Preparação de Amostras. 2010. Disponível em: https://edisciplinas.usp.br/pluginfile.php/4313798/mod_resource/content/1/APOSTILA_MET ALOGRAFIA.pdf. Acesso em: 22 maio 2019 
ROSARIO, A. Estudo de efeitos de elementos de liga na solidificação de um ferro fundido cinzento via análise térmica. 2012. Disponível em:

tede2.uepg.br/jspui/bitstream/prefix/1448/1/Adriano\%20Murilo\%20Rosario.pdf. Acesso em: 16 maio 2019.

SCHEID, A. Ferros Fundidos Ciência dos Materiais PG-MEC. 2010. Disponível em: http://ftp.demec.ufpr.br/disciplinas/EME774/Aula\%2012_FOFOS.pdf. Acesso em: 22 maio 2019

Ferros Fundidos. DEMEC-UFPR. 2016. Disponível em:

ftp.demec.ufpr.br/disciplinas/TM052/Prof.Sheid/3Ferros\%20Fundidos_completo.pdf. P.2. Acesso em: 22 maio 2019

SILVA, J. A. Análise Térmica na Solidificação de Ferros Fundidos Cinzentos Hipoeutéticos. 2007. Disponível em:

http://repositorio.unicamp.br/bitstream/REPOSIP/264734/1/Silva_JorgeAyrtonda_M.pdf. Acesso em: 22 maio 2019

VIDAL, D.F. Análise de estrutura e propriedades mecânica de um ferro fundido nodular em processo de fundição produzido pela técnica de imersão de sino. Universidade Estadual do Norte Fluminense Darcy Ribeiro (UENF). 2013. Disponível em: http://uenf.br/posgraduacao/engenharia-de-materiais/wpcontent/uploads/sites/2/2013/07/ANÁLISE-DE-ESTRUTURA-E-PROPRIEDADESMEC\%C3\%82NICAS-DE-UM-FERRO-FUNDIDO-NODULAR-EM-PROCESSO-DEFUNDI\%C3\%87\%C3\%83O-PRODUZIDO-PELA-T\%C3\%89CNICA-1.pdf. Acesso em: 24 maio 2019 